\title{
Fungal peritonitis in children on peritoneal dialysis at a tertiary care Centre
}

\author{
Mohammed Alsuhaibani ${ }^{1,2^{*}}$, Egab Aldosari ${ }^{3}$, Khawla A. Rahim ${ }^{4}$, Saeed Alzabli ${ }^{4}$ and Dayel Alshahrani ${ }^{2}$
}

\begin{abstract}
Background: Fungal peritonitis (FP) is an infrequent but serious complication in children undergoing peritoneal dialysis (PD). This study aimed to explore the risk factors, clinical manifestations, causative organisms, fungal susceptibility findings, and outcomes of FP in children from Saudi Arabia.

Methods: In this case-control study, the medical records and laboratory results of paediatric patients aged 0-14 years who underwent PD were reviewed for FP episodes. All FP episodes were matched with PD-related bacterial peritonitis episodes (1:4 ratio).

Results: A total of 194 episodes of PD-related peritonitis occurred between 2007 and 2017, among which 11 were FP episodes (5.6\%), representing a rate of 0.03 episodes per patient-year. Of these 11 episodes, 9 were caused by Candida species (82\%). Compared with the bacterial peritonitis group, the FP group had a higher proportion of patients with congenital/infantile nephrotic syndrome $(p=0.005)$ and those younger than 5 years of age $(p=0.001)$. We observed a higher rate of catheter removal in the FP group than in the bacterial peritonitis group $(p<0.001)$; however, 1 patient died despite catheter removal. Moreover, $75 \%$ of Candida species isolates were susceptible to fluconazole.

Conclusions: This study revealed that FP is associated with a significant risk of peritoneal membrane failure among children undergoing PD. Therefore, early diagnosis and prompt management are essential. We also found that congenital/infantile nephrotic syndrome and young age (5 years old or younger) were risk factors for FP in children undergoing PD.
\end{abstract}

Keywords: Peritoneal, Nephrotic, Candida, Catheter, Dialysis, Fungal

\section{Background}

Peritoneal dialysis (PD) is the best procedure for children with end-stage renal disease. Peritonitis is the most common complication in patients on PD, with a higher frequency in children than in adults, and it is the most frequent cause of treatment failure and mortality in patients on PD $[1,2]$.

The causative pathogens and patient susceptibility to PD-related peritonitis vary from time to time and from

\footnotetext{
* Correspondence: msuhaibani@qumed.edu.sa

'Department of Paediatrics, College of Medicine, Qassim University, P.O. Box 6666, Buraidah, Qassim 51452, Saudi Arabia

${ }^{2}$ Department of Paediatric Infectious Diseases, King Fahad Medical City, Riyadh, Saudi Arabia

Full list of author information is available at the end of the article
}

region to region; hence, the International Society for Peritoneal Dialysis (ISPD) endorses the use of empirical antimicrobial medication to treat PD-related peritonitis depending on the region [3]. In children, PD-related bacterial peritonitis is the most frequently identified form of peritonitis, while peritonitis caused by fungal organisms account for $2-12.9 \%$ of all cases. PD-related fungal peritonitis (FP) has a higher morbidity and mortality than bacterial peritonitis. Candida species, especially the non-albicans species, are the most frequent organisms causing PD-related FP in adults and children [4]. Peritonitis caused by fungi such as Aspergillus, Fusarium, Rhodotorula, Mucorales, and dematiaceous moulds were reported periodically [5, 6]. PD-related FP could be a consequence of unsterile techniques during

(c) The Author(s). 2020 Open Access This article is licensed under a Creative Commons Attribution 4.0 International License, which permits use, sharing, adaptation, distribution and reproduction in any medium or format, as long as you give appropriate credit to the original author(s) and the source, provide a link to the Creative Commons licence, and indicate if changes were made. The images or other third party material in this article are included in the article's Creative Commons licence, unless indicated otherwise in a credit line to the material. If material is not included in the article's Creative Commons licence and your intended use is not permitted by statutory regulation or exceeds the permitted use, you will need to obtain permission directly from the copyright holder. To view a copy of this licence, visit http://creativecommons.org/licenses/by/4.0/. The Creative Commons Public Domain Dedication waiver (http://creativecommons.org/publicdomain/zero/1.0/) applies to the data made available in this article, unless otherwise stated in a credit line to the data. 
PD preparation, catheter exit-site infection, intestinal perforation, or fistulae between the genitourinary/gastrointestinal system and the peritoneum. Exposure to bacterial infection and recent use of antibiotics have also been considered as risk factors, especially if the exposure is within 30 days of an FP episode. Age is another risk factor: children below the age of 2 years are at a greater risk of developing FP [4]. Moreover, prolonged hospitalization and poor outcomes, such as peritoneal membrane failure, are associated with FP in paediatric patients undergoing PD [7-9].

In Saudi Arabia, there have been few studies on PD-related peritonitis and its outcomes in children. PD-related FP has been identified in up to $8 \%$ of total peritonitis cases in local observational studies [10-12]. This study aimed to explore the risk factors, clinical manifestations, causative organisms, fungal susceptibility findings, and outcomes of FP in paediatric patients who underwent PD at a tertiary care centre in Saudi Arabia.

\section{Methods}

This was a retrospective case-control study of all episodes of FP occurring in children aged 0-14 years who underwent PD between January 2007 and December 2017 at King Fahad Medical City, Riyadh, Saudi Arabia. Electronic medical records were reviewed for demographic data, age at peritonitis episode, sex, primary diagnosis, number of peritonitis episodes, prior antibiotic use, clinical manifestation, dialysate analysis, causative fungal species, susceptibility results, outcomes of peritonitis, complete blood count, and serum electrolyte levels. The diagnosis of PD-related peritonitis was defined based on the 2016 International Society For Peritoneal Dialysis ISPD recommendation [3], and confirmed when at least 2 of the following characteristics were present: (1) manifestation compatible with peritonitis (abdominal pain and/or cloudy dialysis effluent); (2) effluent dialysis leukocyte count greater than $100 / \mu \mathrm{L}$ (at least $2 \mathrm{~h}$ after a dwell time) with more than $50 \%$ of polymorphonuclear cells; and (3) a positive culture from dialysis effluent.

In the laboratory, peritoneal dialysis effluent samples were tested for white blood cell count, differential count, and Gram staining, and were then inoculated into BACTEC Peds Plus/F media (BD BACTEC FX Blood Culture Instrument; Becton Dickinson, Franklin Lakes, NJ, USA). The remaining suspension was inoculated into blood agar, MacConkey agar, chocolate agar, and Schindler's agar for anaerobic culture.

Fungal cultures were obtained using Sabouraud dextrose agar. Additionally, a germ tube test was used to identify Candida albicans, and an API 20C AUX strip (bioMérieux, Paris, France) was used to identify other Candida species. Mueller-Hinton agar with $2 \%$ glucose was used for antifungal susceptibility testing. A breakpoint reference recommended by the Clinical and Laboratory Standards Institute (CLSI M27-S4) was used to determine the minimal inhibitory concentration for antifungal susceptibility of yeasts.

All patients underwent surgical catheter insertion and received antibiotic prophylaxis at catheter implantation. As per ISPD guidelines, topical antibiotics were applied to the catheter exit site for all patients. Peritonitisrelated death was recorded if death occurred during the peritonitis treatment course.

All FP episodes were matched at a 1:4 ratio with PDrelated bacterial peritonitis episodes. All control patients were diagnosed and hospitalized in the same institution and were under 14 years of age.

A data collection sheet was designed for this study, consisting of 3 sections that included 33 items. Count with percentage was determined for patient demographics, primary diagnosis, comorbidities, laboratory parameters, and outcomes. Fisher's exact test was used for comparisons of percentages between the FP and bacterial peritonitis groups. We used SPSS software (version 26, IBM, Armonk, NY, USA) for statistical analyses. A $p$ value $<0.05$ was considered statistically significant.

\section{Results}

A total of 194 episodes of PD-related peritonitis occurred between 2007 and 2017, among which 11 were FP episodes, representing a rate of 0.03 episodes per patientyear. Of the 10 patients, 7 of the patients were females.The patients age at FP episodes were $0-12$ months (2 episodes) 13-36 months (6 episodes), and more than 36 months ( 3 episodes). The mean age at FP was 38 months (standard deviation, 35.9). Also, 9 patients had a single episode, and 1 (patient 9) had 2 episodes (Table 1). The primary diagnoses of the 10 patients were as follows: congenital nephrotic syndrome in 4 patients, infantile nephrotic syndrome in 2 patients, polycystic kidney disease in 2 patients, hypoplastic kidney in 1 patient, and a single dysplastic kidney in 1 patient. The most frequent comorbidities were hypertension (6 patients), congenital cardiac disease (6 patients), and liver and neurological diseases ( 3 patients).

The clinical presentation consisted of fever in 7 episodes, abdominal pain in 6 episodes, cloudy effluent in 5 episodes, diarrhoea in 4 episodes, and vomiting in 4 episodes. No associated bloodstream infections were documented during the 11 episodes.

Eight of the episodes were preceded by an incidence of peritonitis, while the remaining 3 occurred as the first episode of peritonitis. In all patients, the white blood cell count in the PD effluent was greater than $100 / \mu \mathrm{L}$ and the neutrophil count was greater than $50 \%$. Prior antibiotic use within 1 month of an FP episode was recorded in 4 episodes. All these patients had received antifungal 
Table 1 Patients primary diagnosis and microbiological characteristics of each FP episode $(n=11)$

\begin{tabular}{|c|c|c|c|c|c|c|c|c|c|c|}
\hline $\begin{array}{l}\text { Primary } \\
\text { Diagnosis }\end{array}$ & $\begin{array}{l}\text { Time between } \\
\text { PD insertion } \\
\text { and first FP } \\
\text { (Months) }\end{array}$ & $\begin{array}{l}\text { Previous } \\
\text { Peritonitis }\end{array}$ & $\begin{array}{l}\text { Anti-fungal } \\
\text { Prop. }\end{array}$ & G Tube & $\begin{array}{l}\text { Culture and } \\
\text { Sensitivity }\end{array}$ & $\begin{array}{l}\text { Duration } \\
\text { of Therapy } \\
\text { (Weeks) }\end{array}$ & $\begin{array}{l}\text { Antimicrobial } \\
\text { Treatment }\end{array}$ & $\begin{array}{l}\text { Route of } \\
\text { Antibiotic } \\
\text { Administration }\end{array}$ & $\begin{array}{l}\text { Outcome of } \\
\text { Peritonitis }\end{array}$ & $\begin{array}{l}\text { Antibiotic Use } \\
1 \text { Month Prior } \\
\text { to FP Episode }\end{array}$ \\
\hline$\overline{\mathrm{SDK}}$ & 1 & Yes & Yes & No & $\begin{array}{l}\text { Candida } \\
\text { albicans }\end{array}$ & 3 & Caspofungin & IV & CRS-HD & Yes \\
\hline CNS & 28 & Yes & No & No & Rhodotorula & 2 & Amphotericin B & IV & CRS-HD & No \\
\hline CNS & 37 & Yes & No & No & $\begin{array}{l}\text { Candida } \\
\text { parapsilosis }\end{array}$ & 2 & Fluconazole & IV/IP & CRS-HD-D & No \\
\hline INS & 20 & Yes & No & Yes & $\begin{array}{l}\text { Aspergillus } \\
\text { flavus }\end{array}$ & 3 & Voriconazole & $\mathrm{PO}$ & CRS-HD ${ }^{a}$ & No \\
\hline PKD & 36 & Yes & Yes & No & $\begin{array}{l}\text { Candida } \\
\text { famata }\end{array}$ & 3 & Amphotericin B & IV & CRS-HD ${ }^{a}$ & Yes \\
\hline HPK & 20 & No & No & No & $\begin{array}{l}\text { Candida } \\
\text { lusitaniae }\end{array}$ & 3 & Caspofungin & IV & CRS-HD & No \\
\hline INS & 2 & Yes & Yes & Yes & $\begin{array}{l}\text { Candida } \\
\text { albicans }\end{array}$ & 2 & Fluconazole & IV & CRS-HD & Yes \\
\hline CNS & 14 & No & No & No & $\begin{array}{l}\text { Candida } \\
\text { dubliniensis }\end{array}$ & 2 & Fluconazole & IV & CRS-HD & No \\
\hline $\mathrm{CNS}^{\mathrm{b}}$ & 12 & No & No & No & $\begin{array}{l}\text { Candida } \\
\text { parapsilosis }\end{array}$ & 2 & Fluconazole & IV/P & CRS-HDa & No \\
\hline$C N S^{b}$ & 16 & Yes & No & No & $\begin{array}{l}\text { Candida } \\
\text { tropicalis }\end{array}$ & 3 & Fluconazole & IV/IP & CRS-HD & No \\
\hline PKD & 21 & Yes & Yes & No & $\begin{array}{l}\text { Candida } \\
\text { famata }\end{array}$ & 4 & Caspofungin & IV & CRS-HD & Yes \\
\hline
\end{tabular}

\footnotetext{
a Temporary haemodialysis

b same patient had 2 FP episodes

FP fungal peritonitis, G tube gastrostomy tube, ep episode, SDK single dysplastic kidney, CNS congenital nephrotic syndrome, INS infantile nephrotic syndrome, $H P K$ hypoplastic kidney, PKD polycystic kidney disease, prop. prophylaxis, CRS-HD catheter removed and patient shifted to haemodialysis, $D$ death, $I V$ intravenous, IP intraperitoneal, $P O$ oral
}

prophylaxis, and 2 of them (patients 4 and 7) had a gastrostomy tube. The identified microorganisms included Candida albicans (2 episodes), C. famata (2 episodes), C. parapsilosis (2 episodes), C. dubliniensis (1 episode), C. lusitaniae (1 episode), C. tropicalis (1 episode), Rhodotorula species (1 episode), and Aspergillus flavus
(1 episode). Antifungal susceptibility results are shown in Table 2.

Most patients received 2-3 weeks of therapy, except for 1 patient who underwent 4 weeks of therapy. With respect to antifungal therapy, 5 patients received fluconazole, 3 received caspofungin, and 2 received amphotericin $B$. The

Table 2 Antifungal Susceptibility $(n=11)$

\begin{tabular}{|c|c|c|c|c|c|}
\hline $\mathrm{C} / \mathrm{S}$ & Fluconazole & Itraconazole & Voriconazole & Amphotericin & Caspofungin \\
\hline Candida albicans & $R$ & ND & S & $S$ & $S$ \\
\hline Rhodotorula & ND & ND & ND & ND & ND \\
\hline Candida parapsilosis & S & S & S & S & $\mathrm{S}$ \\
\hline Aspergillus flavus & ND & ND & ND & ND & ND \\
\hline Candida famata & S & $S$ & ND & $S$ & ND \\
\hline Candida lusitaniae & । & S & 1 & $S^{a}$ & S \\
\hline Candida albicans & S & S & S & S & S \\
\hline Candida dubliniensis & S & S & S & S & S \\
\hline Candida parapsilosis & $S$ & R & S & $S$ & S \\
\hline Candida tropicalis & S & S & S & S & $S$ \\
\hline Candida famata & । & $R$ & ND & S & $\mathrm{S}$ \\
\hline
\end{tabular}

\section{With intrinsic resistance}

$N D$ no data, $R$ resistant, $S$ sensitive, $I$ intermediate 
patient with A. flavus infection received voriconazole. The routes of antifungal administration were intravenous in 6 episodes, intravenous and intraperitoneal in 4 episodes, and oral in 1 episode. In all episodes, the catheters were removed, and the patients were shifted to haemodialysis. For 3 patients, haemodialysis was temporary and was followed by a resumption of PD. Unfortunately, 1 patient died during peritonitis treatment despite catheter removal (Table 1).

A comparison of the demographic characteristics, primary diagnosis, comorbidities, laboratory results, and clinical outcomes between patients with FP and bacterial peritonitis is shown in Table 3. We found a higher

Table 3 comparison between fungal and bacterial peritonitis

\begin{tabular}{|c|c|c|c|}
\hline Variable & $\mathrm{FP} n=11(\%)$ & $\mathrm{BP} n=44(\%)$ & $P$ value \\
\hline \multicolumn{4}{|l|}{ Gender } \\
\hline M & $3(27.3)$ & $25(56.8)$ & 0.100 \\
\hline $\mathrm{F}$ & $8(72.7)$ & $19(43.2)$ & 0.100 \\
\hline \multicolumn{4}{|l|}{ Age at peritonitis episode (years) } \\
\hline Less than 5 & $10(90.9)$ & $14(31.8)$ & 0.001 \\
\hline More than 5 & $1(9.1)$ & $30(68.2)$ & 0.001 \\
\hline \multicolumn{4}{|l|}{ Comorbidities } \\
\hline Hypertension & $8(72.7)$ & $30(68.2)$ & 1.000 \\
\hline Cardiac diseases & $7(63.6)$ & $15(34.1)$ & 0.094 \\
\hline Neurological diseases & $3(27.3)$ & $10(22.7)$ & 0.709 \\
\hline Liver diseases & $3(27.3)$ & $2(4.5)$ & 0.049 \\
\hline \multicolumn{4}{|l|}{ Primary diagnosis } \\
\hline CNS/INS & $7(63.6)$ & $8(18.2)$ & 0.005 \\
\hline HPK & $1(9.1)$ & $2(4.5)$ & 0.495 \\
\hline PKD & $2(18.2)$ & $9(20.5)$ & 1.000 \\
\hline \multicolumn{4}{|l|}{ PD duration (months) } \\
\hline 0_12 & $9(81.8)$ & $12(27.3)$ & 0.001 \\
\hline $13 \_24$ & $0(0)$ & $7(15.9)$ & 0.323 \\
\hline More 24 & $2(18.2)$ & $26(59.1)$ & 0.02 \\
\hline \multicolumn{4}{|l|}{ Effluent analysis } \\
\hline$W C C>100 / \mu \mathrm{L}$ & $11(100)$ & $37(84.1)$ & 0.323 \\
\hline $\mathrm{PMN}>50 \%$ & $11(100)$ & 39 (88.6) & 0.571 \\
\hline \multicolumn{4}{|l|}{ Blood tests } \\
\hline Sodium > $135(\mathrm{mmol} / \mathrm{L})$ & $5(45.5)$ & $12(27.3)$ & 0.286 \\
\hline Potassium> $3.5(\mathrm{mmol} / \mathrm{L})$ & $4(36.4)$ & $19(43.2)$ & 0.745 \\
\hline Albumen > 25 (g/L) & $4(36.4)$ & $26(59.1)$ & 0.198 \\
\hline \multicolumn{4}{|l|}{ Outcome } \\
\hline Resolved & $0(0)$ & $35(79.5)$ & $<0.001$ \\
\hline Catheter removed & $10(90.9)$ & $9(20.5)$ & $<0.001$ \\
\hline Death & $1(9.1)$ & $0(0)$ & 0.200 \\
\hline
\end{tabular}

$F P$ fungal peritonitis, $B P$ bacterial peritonitis, $M$ male, $F$ female, $S D K$ single dysplastic kidney, CNS congenital nephrotic syndrome, INS infantile nephrotic syndrome, HPK hypoplastic kidney, PKD polycystic kidney disease, $P D$ peritoneal dialysis, WCC white cell count, PMN Polymorphonuclear neutrophils proportion of patients younger than 5 years of age in the FP group. Additionally, the FP group had a higher proportion of patients with congenital/infantile nephrotic syndrome and patients with liver diseases as a comorbidity $(p=0.005)$. PD duration was associated with fungal peritonitis in the first 12 months of dialysis. Regarding the peritonitis outcome, patients with FP had a higher rate of catheter removal than those with bacterial peritonitis $(p<0.001)$. There was no significant difference in sex, effluent analysis results, or serum laboratory test findings between the groups.

\section{Discussion}

FP is an infrequent but serious complication of PD and is concomitant with a high percentage of temporary or permanent membrane failure requiring haemodialysis. Furthermore, increased rates of hospitalization, morbidity, and mortality are reported in cases of FP. The initial presentation of FP is similar to that of peritonitis caused by bacterial organisms, which hinders early diagnosis when fungal culture is not performed [13]. To our knowledge, this is the first study describing FP and antifungal susceptibility in paediatric patients undergoing PD in Saudi Arabia. Moreover, the literature on the prevalence and outcomes of FP in children is limited.

Recently, Munshi et al. described FP outcomes of patients enrolled in the Standardizing Care to Improve Outcomes in Paediatric End Stage Renal Disease (SCOPE) Collaborative. They found that almost $60 \%$ of patients were younger than 2 years of age and gastrostomy tube was used in $50 \%$ of FP patients [4]. In the current study, we found that children below 5 years of age formed the majority of FP patients and gastrostomy was used only in 2 patients. Bladder and bowel incontinency might represent a risk for infection in the younger population.

In the North American Paediatric Renal Trials and Collaborative Study (NAPRTCS), the largest study on FP in PD patients aged 21 years or younger, Warady et al. found recent antibiotic use was observed in 56\% of episodes [8].. In our study, recent antibiotic use was observed in only $36 \%$ of all episodes. However, 3 FP episodes in our study were not proceeded by bacterial peritonitis that requires antibiotics, which might be the reason for low recent antibiotic use. Recent antibiotic exposure could predispose patients to FP, as demonstrated in some adult and paediatric observational studies. This susceptibility may be explained by the overgrowth of fungi in the gastrointestinal system due to antibiotic use, which leads to transmural migration of fungi to the peritoneal cavity [14, 15].

Published study showed different rate of FP among paediatric patients on PD. In our study, FP rate was $5.6 \%$, lower than the rate of the Iranian and SCOPE studies (12.9 and 8\%, respectively) [4, 8, 16, 17]. We 
believe that the FP rate may be different from region to region due to various risk factors and access to medical care.

Interestingly, in the current study, the primary diagnoses of congenital, and infantile nephrotic syndrome were the most common primary diagnosis, which is significantly different from the observation in patients with bacterial peritonitis. Patients with congenital nephrotic syndrome have higher risks of infection and PD-related peritonitis than other patients with renal disease. The early start of PD in patients with congenital nephrotic syndrome makes them susceptible to frequent infections. Other risk factors include albumin loss and low immunoglobulin concentrations. However, Dufek et al. reported that most cases of PD-related peritonitis in patients with congenital nephrotic syndrome are bacterial, and the peritonitis rate in these patients is 0.77 per patient-year. In an observational study, invasive candidiasis was found in $3 \%$ of patients with congenital nephrotic syndrome who had started PD before 1 year of age, and 5 out of 7 patients had previous bacterial peritonitis before an FP episode [18, 19]. However, low albumin concentration was not significantly different between fungal and bacterial peritonitis, which has been linked with a risk of technique failure [20].

In our study, peritonitis episodes caused by Candida species and the non-albicans types were the most predominant. Almooosa et al. found that the most common invasive Candida species in paediatric patients was C. albicans, which accounted for $53 \%$ of cases, while $C$. parapsilosis $(21 \%)$ and C. tropicalis (10\%) were the most predominant non-albicans species in the same centre. Susceptibility testing for invasive candidiasis revealed a high susceptibility of Candida species to amphotericin B (97.6\%), followed by caspofungin (96.3\%), and fluconazole (78\%). A similar finding was observed in our peritoneal fluid Candida species isolates: susceptibility to amphotericin B and caspofungin was $100 \%$, while susceptibility to fluconazole was $78 \%$. Surprisingly, a Canadian study reported 9 episodes of FP due to Candida species, in which 3 isolates (C. tropicalis, 1 ; $C$. parapsilosis, 1 ; C. glabrata, 1) were resistant to amphotericin $B[21,22]$. Understanding the regional fungal susceptibility is essential for early administration of appropriate antifungals, which has an impact on the outcome of peritonitis.

In this study, catheter removal was necessary in $91 \%$ of episodes, which is consistent with the findings of the SCOPE and NAPRTCS studies. In a previous retrospective study, the FP mortality rate was $2.9 \%$, while we observed only 1 death during FP [4, 22]. The mortality rate in the adult population with $\mathrm{FP}$ was reported to be higher than that in the paediatric age group $(15-50 \%$ vs. $0-6 \%$, respectively) [16].
Current guidelines recommend starting antifungal therapy and prompting PD catheter removal, which could improve the outcome of PD-related FP episodes because knowing the local epidemiology of a fungal infection is very helpful for the empirical use of antifungals. Antifungal prophylaxis during bacterial peritonitis treatment is still controversial, although it is recommended in ISPD guidelines based on randomized trials [3, 23, 24].

The retrospective design and the possibility of potential bias in the matching of fungal to bacterial peritonitis using the peritoneal dialysis database are some limitations of this study. Additionally, the small number of FP episodes did not allow the use of multivariate analysis. Nonetheless, this is the first study reporting PD-related FP occurrence in Saudi Arabia.

\section{Conclusions}

This study revealed that FP is associated with a significant risk of peritoneal membrane failure among children undergoing PD. Therefore, early diagnosis and prompt management are essential. We also found that congenital/infantile nephrotic syndrome and young age (5 years old or younger) were risk factors for FP in children undergoing PD.

This was a single-centre study; hence, our findings cannot be generalized. Moreover, due to the rarity of FP, the total number of cases was limited. A multicentre, prospective cohort study is recommended for better identification of the risk factors and outcomes of PDrelated FP.

\section{Abbreviations \\ FP: Fungal Peritonitis; PD: Peritoneal Dialysis; ISPD: International Society for Peritoneal Dialysis; SCOPE: Standardizing Care to Improve Outcomes In Paediatric End Stage Renal Disease; NAPRTCS: North American Paediatric Renal Trials and Collaborative Study; CLSI: Clinical and Laboratory Standards Institute; SPSS: Statistical Package for The Social Sciences}

\section{Acknowledgements}

We would like to thank Sibi Varghese, Vernice Rose for their support and assistance.

\section{Authors' contributions}

MA designed the study. SA \& EA made data analysis. Literature search and the manuscript drafting done by MA \& SA. DA \& KA participated in manuscript writing and revision. All authors have read and approved the final manuscript.

\section{Funding}

None.

\section{Availability of data and materials}

The data and material of the study are available from the corresponding author MA on request.

\section{Ethics approval and consent to participate}

The clinical data and laboratory information were retrospectively obtained from patient medical records. Ethics approval was obtained from the King Fahad Medical City institutional review board in Riyadh, Saudi Arabia (IRB\# 18-344). Informed consent was not required because of the retrospective cohort design of this study, lack of patient intervention and all patients' data were de-identified. 


\section{Consent for publication}

Not applicable.

\section{Competing interests}

The authors declare that they have no conflicts of interest.

\section{Author details}

'Department of Paediatrics, College of Medicine, Qassim University, P.O. Box 6666, Buraidah, Qassim 51452, Saudi Arabia. ${ }^{2}$ Department of Paediatric Infectious Diseases, King Fahad Medical City, Riyadh, Saudi Arabia. ${ }^{3}$ General Paediatric Department, King Fahad Medical City, Riyadh, Saudi Arabia. ${ }^{4}$ Department of Paediatric Nephrology, King Fahad Medical City, Riyadh, Saudi Arabia.

Received: 31 July 2019 Accepted: 10 August 2020

Published online: 16 September 2020

\section{References}

1. Fraser N, Hussain FK, Connell R, et al. Chronic peritoneal dialysis in children. Int J Nephrol Renovasc Dis. 2015;8:125-37.

2. Lee KO, Park SJ, Kim JH, et al. Outcomes of peritonitis in children on peritoneal dialysis: a 25-year experience at severance hospital. Yonsei Med J. 2013:54:983-9.

3. Li PK, Szeto CC, Piraino B, et al. ISPD peritonitis recommendations: 2016 update on prevention and treatment. Perit Dial Int. 2016;36:481-508.

4. Munshi R, Sethna CB, Richardson T, et al. Fungal peritonitis in the standardizing care to improve outcomes in pediatric end stage renal disease (SCOPE) collaborative. Pediatr Nephrol. 2018;33:873-80.

5. Schwetz I, Horina J, Buzina W, et al. Aspergillus oryzae peritonitis in CAPD: case report and review of the literature. Am J Kidney Dis. 2007;49:701-4.

6. Cheng IK, Fang GX, Chan TM, et al. Fungal peritonitis complicating peritoneal dialysis: report of 27 cases and review of treatment. Q J Med. 1989:71:407-16.

7. Sethna CB, Bryant $K$, Munshi R, et al. Risk factors for and outcomes of catheter-associated peritonitis in children: the SCOPE collaborative. Clin J Am Soc Nephrol. 2016;11:1590-6.

8. Warady BA, Bashir M, Donaldson LA. Fungal peritonitis in children receiving peritoneal dialysis: a report of the NAPRTCS. Kidney Int. 2000;58:384-9.

9. Prasad N, Gupta A. Fungal peritonitis in peritoneal dialysis patients. Perit Dial Int. 2005:25:207-22.

10. Alharthi AA. Peritonitis in children with automated peritoneal dialysis. Clin Nephrol. 2015:84:289-94

11. Kari JA. Peritoneal dialysis in children. Saudi J Kidney Dis Transplant. 2005;16: 348-53.

12. Mirza K, Elzouki AY. Peritonitis in continuous ambulatory peritoneal dialysis in children living in Saudi Arabia. Pediatr Nephrol. 1997;11:325-7.

13. Matuszkiewicz-Rowinska J. Update on fungal peritonitis and its treatment. Perit Dial Int. 2009;29:S161-5.

14. Goldie SJ, Kiernan-Troidle L, Torres C, et al. Fungal peritonitis in a large chronic peritoneal dialysis population: a report of 55 episodes. Am J Kidney Dis. 1996;28:86-91.

15. Mocan H, Murphy AV, Beattie TJ, et al. Fungal peritonitis in children on continuous ambulatory peritoneal dialysis. Scott Med J. 1989;34:494-6.

16. Raaijmakers R, Schröder C, Monnens L, et al. Fungal peritonitis in children on peritoneal dialysis. Pediatr Nephrol. 2007:22:288-93.

17. Hooman N, Madani A, Sharifian MD, et al. Fungal peritonitis in Iranian children on continuous ambulatory peritoneal dialysis: a national experience. Iran J Kidney Dis. 2007;1:29-33.

18. Dufek S, Holtta T, Trautmann A, et al. Management of children with congenital nephrotic syndrome: challenging treatment paradigms. Nephrol Dial Transplant. 2019;34:1369-77.

19. Ljungberg $\mathrm{P}$, Holmberg $\mathrm{C}$, Jalanko $\mathrm{H}$. Infections in infants with congenital nephrosis of the Finnish type. Pediatr Nephrol. 1997;11:148-52.

20. Gulati S, Stephens D, Balfe JA, et al. Children with hypoalbuminemia on continuous peritoneal dialysis are at risk for technique failure. Kidney Int. 2001;59:2361-7.

21. Almooosa Z, Ahmed GY, Omran A, et al. Invasive candidiasis in pediatric patients at king Fahad Medical City in Central Saudi Arabia: a 5-year retrospective study. Saudi Med J. 2017;38:1118-24.
22. Levallois J, Nadeau-Fredette AC, Labbé AC, et al. Ten-year experience with fungal peritonitis in peritoneal dialysis patients: antifungal susceptibility patterns in a north-American center. Int J Infect Dis. 2012;16:e41-3.

23. Lo WK, Chan CY, Cheng SW, et al. A prospective randomized control study of oral nystatin prophylaxis for Candida peritonitis complicating continuous ambulatory peritoneal dialysis. Am J Kidney Dis. 1996;28:549-52.

24. Restrepo C, Chacon J, Manjarres G. Fungal peritonitis in peritoneal dialysis patients: successful prophylaxis with fluconazole, as demonstrated by prospective randomized control trial. Perit Dial Int. 2010;30:619-25.

\section{Publisher's Note}

Springer Nature remains neutral with regard to jurisdictional claims in published maps and institutional affiliations.
Ready to submit your research? Choose BMC and benefit from:

- fast, convenient online submission

- thorough peer review by experienced researchers in your field

- rapid publication on acceptance

- support for research data, including large and complex data types

- gold Open Access which fosters wider collaboration and increased citations

- maximum visibility for your research: over $100 \mathrm{M}$ website views per year

At BMC, research is always in progress.

Learn more biomedcentral.com/submissions 